\title{
INDUCTION THERAPY WITH THE SELECTIVE INTERLEUKIN-23 INHIBITOR RISANKIZUMAB IN PATIENTS WITH MODERATE-TO- SEVERE CROHN'S DISEASE: A RANDOMISED, DOUBLE-BLIND, PLACEBO-CONTROLLED PHASE 2 STUDY
}

Brian G Feagan, William j Sandbom, Geert D'Haens, Julian Panés, Arthur Kaser, Marc Ferrante, Edouard Louis, Denis Franchimont, Olivier Dewit, Ursula Seidler, Kyung-jo Kim, Markus F Neurath, Stefan Schreiber, Paul Scholl, Chandrasena Pamulapati, Bojan Lalovic, Sudha Visvanathan, Steven j Padula, Ivona Herichova, Adina Soaita, David B Hall, Wulf O Böcher

Western University, Robarts Clinical Trials, London, ON, Canada (B G Feagan MD); IBD Center, University of California San Diego and UC San Diego Health System, San Diego, CA, USA(W J Sandborn MD); Academic Medical Center, University of Amsterdam, Amsterdam, Netherlands (Prof G D'Haens PhD); Hospital Clinic Barcelona, IDIBAPS, CIBE Rehd, Barcelona, Spain (Prof J Panés MD); University of Cambridge, Addenbrooke's Hospital, Cambridge, UK (Prof A Kaser MD); University Hospitals Leuven, Leuven, Belgium (Prof M Ferrante PhD); University Hospital CHU Liège, Liège, Belgium (Prof E Louis PhD); Erasme University Hospital, Brussels, Belgium (Prof D Franchimon tMD); Cliniques Universitaires Saint-Luc, Brussels, Belgium (Prof O Dewit MD); Hannover Medical School, Hannover, Germany (Prof U Seidler MD); Asan Medical Center, Seoul, South Korea (Prof K-J Kim); University of Erlangen-Nurnberg, Erlangen, Germany (Prof M F Neurath MD); Christian-AlbrechtsUniversity Kiel, Kiel, Germany (Prof S Schreiber MD); Boehringer Ingelheim Pharmaceuticals, Ridgefield,CT,USA (P Scholl M B B Chir, C Pamulapati PhD, B Lalovic PhD, S Visvanathan PhD, A Soaita PhD, DB Hall PhD); Boehringer Ingelheim Pharma GmbH, Ingelheim, Germany (S J Padula $M D$, Prof W O Böcher MD); and Boehringer Ingelheim RCV GmbH, Vienna, Austria (I HerichovaPhD)

\section{SUMMARY}

Background The interleukin-23 pathway is implicated genetically and biologically in the pathogenesis of Crohn's disease. We aimed to assess the efficacy and safety of risankizumab (BI 655066, Boehringer Ingelheim, Ingelheim, Germany), a humanised monoclonal antibody targeting the p19 subunit of interleukin-23, in patients with moderately-to-severely active Crohn's disease.

Methods In this randomised, double-blind, placebo-controlled phase 2 study, we enrolled patients at 36 referral sites in North America, Europe, and south-east Asia. Eligible patients were aged 18-75 years, with a diagnosis of Crohn's disease for at least 3 months, assessed as moderate-to-severe Crohn's disease at screening, defined as a Crohn's Disease Activity Index (CDAI) of 220-450, with mucosal ulcers in the ileum or colon, or both, and a Crohn's Disease Endoscopic Index of Severity (CDEIS) of at least 7 ( $\geq 4$ for patients with isolated ileitis) on ileocolonoscopy scored by a masked central reader. Patients were randomised 1:1:1 using an interactive response system to a double-blind investigational product, and stratified by previous exposure to TNF antagonists (yes vs no). Patients received intravenous $200 \mathrm{mg}$ risankizumab, $600 \mathrm{mg}$ risankizumab, or placebo, at weeks 0,4 , and 8 . The primary outcome was clinical remission (CDAl <150) at week 12 (intention-to-treat population). Safety was assessed in patients who received at least one dose of study drug. This study is registered with ClinicalTrials.gov, number NCT02031276.

Findings Between March, 2014, and September, 2015, 213 patients were screened, and 121 patients randomised. At baseline, 113 patients $(93 \%)$ had been previously treated with at least one tumour necrosis factor (TNF) antagonist (which had failed in 96 [79\%]). At week 12, 25 (31\%) of 82 risankizumab patients (pooled 41 patients in $200 \mathrm{mg}$ and 41 patients in $600 \mathrm{mg}$ arms) had clinical 
remission versus six (15\%) of 39 placebo patients (difference vs placebo $15 \cdot 0 \%, 95 \% \mathrm{Cl} 0 \cdot 1$ to $30-1$; $\mathrm{p}=0.0489)$. Ten (24\%) of 41 patients who received $200 \mathrm{mg}$ risankizumab had clinical remission $(9-0 \%$, $-8-3$ to $26-2 ; p=0.31)$ and $15(37 \%)$ of 41 who received the $600 \mathrm{mg}$ dose $(20.9 \%, 2.6$ to $39 \cdot 2$; $\mathrm{p}=0.0252) .95$ (79\%) patients had adverse events (32 in the placebo group, 32 randomised to $200 \mathrm{mg}$ risankizumab, 31 randomised to $600 \mathrm{mg}$ risankizumab); 18 had severe adverse events (nine, six, three); 12 discontinued (six, five, one); 24 had serious adverse events (12, nine, three). The most common adverse event was nausea and most common serious adverse event was worsening of underlying Crohn's disease. No deaths occurred.

Interpretation In this short-term study, risankizumab was more effective than placebo for inducing clinical remission in patients with active Crohn's disease. Therefore, selective blockade of interleukin23 via inhibition of p19 might be a viable therapeutic approach in Crohn's disease.

\section{Research in context}

\section{EVIDENCE BEFORE THIS STUDY}

We searched PubMed for English language articles using the terms "Crohn's disease", "biologictherapy", "adalimumab", "infliximab", "certolizumab pegol", "vedolizumab", "ustekinumab", and "IL-23" to identify controlled clinical trials published up to June 17,2016, with no start date restrictions. Biological therapies approved for Crohn's disease include the tumour necrosis factor (TNF) antagonists adalimumab, infliximab, and certolizumab pegol. Treatment with these drugs has resulted in some induction of clinical remission inTNF antagonist-naive patients. Treatment with a secondTNF antagonist is effective in patients who have lost response or were intolerant to their previous TNF antagonist, but a response to a second TNF antagonist after primary TNF antagonist failure is not well studied and is generally very low. The integrin inhibitor vedolizumab has been approved for Crohn's disease.

The interleukin-23 pathway is implicated in the pathogenesis of psoriasis and Crohn's disease. Biological agents that abrogate this axis, through targeted inhibition of interleukin 17 orthe interleukin 17 receptor, interleukin 23, or interleukin 12 and interleukin 23, have shown efficacy in clinical trials for the treatment of psoriasis.

\section{ADDED VALUE OF THIS STUDY}

In this proof-of-concept phase 2 clinical trial for risankizumab, a monoclonal antibody that targets the interleukin-23 p19 subunit, in treatment-experienced patients with moderate-to-severe Crohn's disease, risankizumab was superiorto placebo in achieving clinical response or remission at week 12 in patients with moderate-to-severe Crohn's disease.

\section{IMPLICATIONS OF ALL THE AVAILABLE EVIDENCE}

Biological agents that abrogate the interleukin-23 pathway axis have shown efficacy in clinical trials for the treatment of psoriasis, but agents that specifically target interleukin 17 or the interleukin 17 receptor exacerbate Crohn's disease, indicating a dichotomy between the activity of interleukin 12/ interleukin 23 and interleukin 17 in psoriasis versus Crohn's disease. Ourtrial of risankizumab in treatment-experienced patients with moderate-to-severe Crohn's disease suggests that specific blockade of interleukin 23 with risankizumab might be a promising new therapeutic approach with a unique mode of action forthe treatment of this serious chronic disease. 


\section{Introduction}

Crohn's disease is a chronic inflammatory bowel disease characterised by ulceration and transmural inflammation. ${ }^{1}$ Management consists of controlling inflammation through administration of broadly acting immunosuppressive drugs such as corticosteroids, thiopurines, or methotrexate, or selective targeting of cytokines or integrins with biological agents. ${ }^{2-4}$ These therapies are not consistently effective and can cause adverse events including infection. ${ }^{4-6}$ About a third of patients treated with a TNF antagonist show a primary non-response, with another third developing secondary failure or intolerance to treatment. Patients with primary non-response or secondary failure to a TNF antagonist have a lower chance of responding to subsequent treatment with different TNF antagonists or the integrin antagonist vedolizumab.

Interleukin-23 receptor gene polymorphisms are associated with susceptibility to Crohn's disease, and interleukin-23 is a key regulator of the T-helper-17 cell (ThI7) and type 3 innate lymphoid cell (ILC3) pathways that contribute to inflammatory cytokine production and tissue inflammation. ${ }^{7-9}$ The interleukin-23 pathway is implicated in the pathogenesis of several immune-mediated chronic inflammatory diseases including psoriasis and Crohn's disease. Biological agents that abrogate this axis, either through targeted inhibition of the interleukin-17/interleukin-17 receptor (brodalumab, ixekizumab, secukinumab), interleukin-23 (guselkumab, risankizumab, tildrakizumab), or interleukin-12 and interleukin-23 (ustekinumab), have shown efficacy in clinical trials for the treatment of psoriasis. ${ }^{10}$ In Crohn's disease, interleukin 12 and interleukin-23 p40 subunit inhibition by ustekinumab appears beneficial with effect sizes for induction of clinical remission of $9-18 \%$ in patients with previous tumour necrosis factor (TNF) antagonist failure and $23-27 \%$ in TNF-antagonist-experienced patients. ${ }^{11,12}$ However, whether its efficacy is driven by the inhibition of interleukin-12, interleukin-23, or both cytokines, is unclear. In the absence of direct comparator trials, these effect sizes must be interpreted with caution while considering the differences in study population and design that affect such crosstrial comparison. By contrast, agents that specifically target interleukin-17 or interleukin-17 receptor exacerbate Crohn's disease, indicating a dichotomy between the activity of interleukin-12/interleukin23 and interleukin-17 in psoriasis versus Crohn's disease. ${ }^{13,14}$ To our knowledge, no treatments that specifically target interleukin-23 in Crohn's disease are approved and only limited clinical trial data for such agents exist.

Risankizumab (BI 655066, Boehringer Ingelheim, Ingelheim, Germany) is a humanised monoclonal antibody that targets the pl9 subunit, which is specific to interleukin-23. ${ }^{15}$ Thus, treatment with risankizumab might downregulate interleukin-23-mediated inflammation without affecting interleukin12-dependent T-cell pathways which, in animal models, are important for infection and cancer immunity. ${ }^{16,17}$ This selective approach might have advantages over agents that target both cytokines.

Preliminary data indicate that risankizumab is an effective treatment for psoriasis, a chronic inflammatory skin disease in which the interleukin-23 pathway is implicated. ${ }^{18}$ On the basis of these observations, we aimed to assess the safety and efficacy of risankizumab in patients with active Crohn's disease.

\section{Methods}

\section{STUDY DESIGN}

In this multicentre, randomised, placebo-controlled, phase 2 study, we enrolled patients at 36 referral sites in North America, Europe, and southeast Asia (appendix). The study had three treatment periods: a 12-week double-blinded intravenous therapy period (period 1); a 12-week open-label intravenous therapy or wash-out period (period 2); and a 26-week subcutaneous therapy period (period 3). We report the primary, secondary, and additional endpoints-including biomarker, pharmacokinetic, and anti-drug antibody assessments-for period 1; endpoints for periods 2 and 3 will be reported after completion of the study. The complete study design is shown in the appendix ( 77$)$. 
The study protocol was approved by the institutional review board or ethics committee at each participating centre. Safety data were periodically evaluated by an independent data monitoring committee.

\section{PATIENTS}

Eligible patients were aged 18-75 years, with a diagnosis of Crohn's disease for at least 3 months that was assessed as moderate-to-severe Crohn's disease at screening, defined as a Crohn's Disease Activity Index (CDAI)19 of 220-450, with mucosal ulcers in the ileum or colon, or both, and a Crohn's Disease Endoscopic Index of Severity (CDEIS)19 of at least 7 ( $\geq 4$ for patients with isolated ileitis) on ileocolonoscopy scored by a masked central reader (descriptions of CDAI and CDEIS are in the appendix, $p$ 5). Patients could have had previous treatment with one or more tumour necrosis factor (TNF) antagonists or vedolizumab. Patients previously treated with ustekinumab were excluded, as were patients who had received any other biological agent (including agents targeting integrins) within 8 weeks or five half-lives before randomisation. Patients continued stable doses of oral corticosteroids, oral 5-aminosalicylates, azathioprine, 6-mercaptopurine, methotrexate, and antibiotics throughout the trial if they were on these at the start. A full description of the inclusion and exclusion criteria is in the appendix (pp 3-4). All patients provided written informed consent.

\section{RANDOMISATION AND MASKING}

Before the first 12-week period, we randomly assigned patients $(1: 1: 1)$ to receive $200 \mathrm{mg}$ risankizumab, $600 \mathrm{mg}$ risankizumab, or placebo. We used an interactive response system to assign a double-blind investigational product to every patient. Randomisation was stratified by previous exposure to TNF antagonists (yes vs no). A randomisation list was generated using a validated system, which involved a pseudorandom number generator to guarantee the reproducibility of the assignments. This randomisation list was checked by an independent statistician and used to assign randomisation numbers to eligible patients. Access to the randomisation code was controlled and documented. All people directly involved in the conduct and analysis of the trial (including patients, investigators, and study personnel) were fully masked to the treatment allocation before the week 12 database lock. To maintain masking, study drug packaging was identical irrespective of treatment and was only distinguishable by medication number, which was managed by the central randomisation centre. Both risankizumab and placebo appeared as clear solutions.

\section{PROCEDURES}

Patients received either $200 \mathrm{mg}$ risankizumab, $600 \mathrm{mg}$ risankizumab, or placebo by intravenous infusion at weeks 0,4 , and 8 (appendix, p 7). Patients were followed through week 12 , every 4 weeks, and were then eligible to enter subsequent phases of the trial.

\section{OUTCOMES}

The primary outcome was clinical remission in the pooled risankizumab dose groups, defined by a CDAI $<150$ at week 12 . Secondary outcomes (all evaluated at week 12) including clinical response (defined by either CDAI $<150$ or a CDAl reduction from baseline of $\geq 100$ ), endoscopic remission (CDEIS score of $\leq 4 ; \leq 2$ for patients with isolated ileitis), endoscopic response ( $>50 \%$ CDEIS reduction from baseline), mucosal healing (absence of mucosal ulceration), and deep remission (clinical remission and endoscopic remission) are reported here. All further endpoints relating to period 1 are listed in the appendix ( $p 4$ ) and will be reported after completion of the study. Of these, we report CDAI throughout period 1, change from baseline to week 12 in Inflammatory Bowel Disease Questionnaire (IBDQ), C-reactive protein (CRP) throughout period 1, and percentage change from baseline in faecal calprotectin (FCP). Additionally, percentage change from baseline in serum interleukin 22 was reported because activated T helper 17 and ILC3 cells from patients with inflammatory bowel disease characteristically produce interleukin 22 , as well as biomarker gene changes to week 12 , 
pharmacokinetic data (where data permitted), and anti-drug antibody assessments. Additional posthoc analyses were the proportion of patients achieving normalisation of CRP and FCP.

Health-related quality of life (HRQoL) was assessed at baseline and at week 12 by asking patients to complete the 32 questions of the IBDQ, which has been established as a valid, reliable, and responsive tool to scale the impact of bowel-related symptoms, systemic complaints, social functions, and emotional status of patients with ulcerative colitis, with higher scores indicating better HRQoL.20

At each study visit, data were obtained for CDAl, adverse events, concomitant medications, FCP, and serum CRP concentration. Biomarkers relevant to the interleukin 23 pathway were evaluated in tissue biopsies obtained at baseline and at week 12, and in whole blood samples (appendix p 5). CDEIS scores and presence or absence of mucosal ulcers were determined by masked central readers at baseline and week 12. Plasma samples for pharmacokinetic analysis and immunogenicity assessments were collected at each visit. The schedule for collection and assay methodology is described in the appendix ( $p p$ 4-5). The anti-drug antibody electro-chemiluminescence assay was sensitive and drug tolerant.

Safety endpoints were adverse events (coded using version 18.1 of the Medical Dictionary for Drug Regulatory Activities [MedDRA], severity grading based on the Rheumatology Common Toxicity Criteria version 2.0), serious adverse events, tolerability changes in vital signs and physical examination, discontinuation of therapy because of adverse events, and laboratory assessments.

\section{Figure 1: Trial profile}

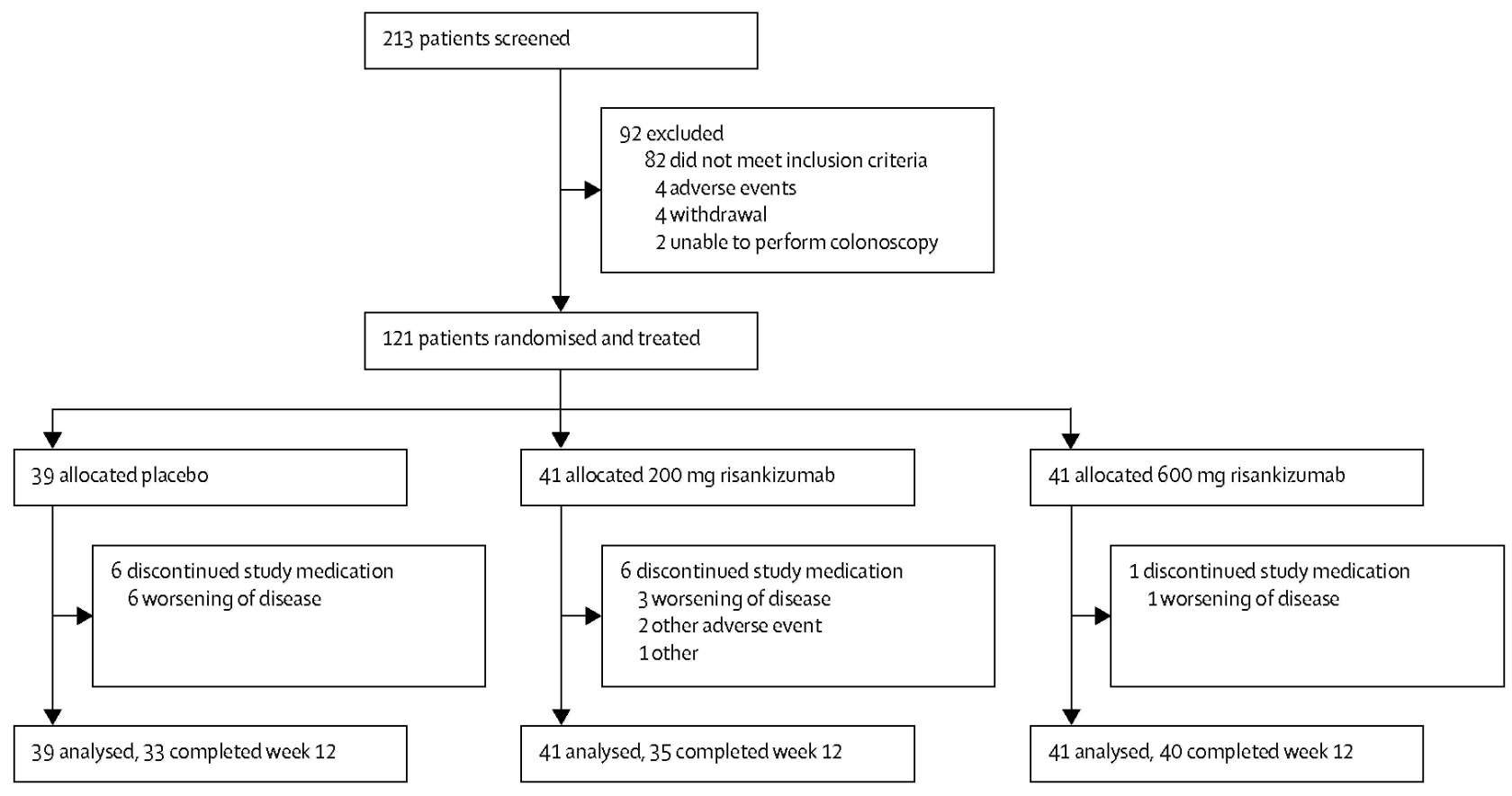

\section{STATISTICAL ANALYSIS}

We analysed the primary and secondary endpoints on an intention-to-treat basis. Pharmacokinetic data, immuno-genicity and biomarker endpoints were analysed on all evaluable patients who received at least one dose of study drug. Differences in pairwise comparisons for the primary and secondary endpoints were analysed using a stratified Cochran-Mantel-Haenszel test, with previous exposure to TNF antagonists as the stratification variable; confidence intervals were calculated by normal approximation of the variance of Mantel-Haenszel stratified risk difference. Continuous outcomes including change or percentage change from baseline in CDAI, CRP, FCP, and plasma interleukin-22 concentrations were summarised descriptively and baseline values were assigned from time of 
treatment initiation; a Wilcoxon two-sample test was used post hoc to compare the median differences from baseline between treatments.

We predicted that both the $200 \mathrm{mg}$ risankizumab and $600 \mathrm{mg}$ risankizumab dose groups would be effective; thus, the primary analysis was based on a comparison of week 12 remission rates in the pooled risankizumab dose groups with placebo. We estimated that randomisation of 120 patients in a 2:1 ratio between risankizumab (200 $\mathrm{mg}$ and $600 \mathrm{mg}$, pooled) and placebo would provide $82 \%$ power using a two-sided test with a type 1 error of $0 \cdot 10$, which we used to increase the sensitivity of identifying a treatment effect for the primary endpoint. A 30\% clinical remission rate for the combined risankizumab dose groups and a $9 \%$ rate for placebo was the basis for the calculation. For secondary endpoints, statistical significance was based on two-sided $p$ values less than $0 \cdot 05$. Non-response imputation was used for missing values and analysis. Patients missing their week 12 CDEIS assessment were counted as endoscopic failures; patients in whom prohibited concomitant medication to treat Crohn's disease was used before week 12 and those with missing CDAl items were considered to be treatment failures. We did not adjust for multiplicity for clinical and endoscopic endpoints; for RNA biomarker analyses, we applied the Bonferroni's correction for multiple comparisons.

Safety analyses included patients who underwent randomisation and received at least one dose of study drug. We report frequencies of adverse events descriptively. This trial is registered with ClinicalTrials. gov, number NCT02031276.

\section{ROLE OF THE FUNDING SOURCE}

The funder of the study was involved in the study design and the data collection and analysis. All authors had full access to all data in the study, made the decision to submit these data for publication, were involved in writing the manuscript, and agreed upon the final content of the paper. The study funder provided funding for editorial assistance in manuscript preparation. The corresponding author had final responsibility for the decision to submit for publication.

\section{Results}

Between March, 2014, and September, 2015, 213 patients were screened and 121 were randomised (figure 1). The main reason for screening failures was insufficient clinical or endoscopic activity. Less frequent reasons included the presence of Crohn's complications, concomitant diseases, or insufficient wash-out time of prohibited medications. 13 patients discontinued study participation before week 12 (figure 1). Baseline demographics and disease characteristics of patients were similar in treatment groups (table 1). Mean duration of Crohn's disease was 13 years (SD 9) at study entry.

Clinical remission at week 12 was achieved by ten (24\%) of 41 patients in the $200 \mathrm{mg}$ risankizumab group and $15(37 \%)$ of 41 patients in the $600 \mathrm{mg}$ risankizumab group, compared with six patients $(15 \%)$ in the placebo group (figure 2, table 2). At week 12, the observed difference between the pooled risankizumab dose groups and placebo was $15.0 \%(95 \% \mathrm{Cl} 0.1$ to $30.1 ; p=0.0489)$. The observed difference between the $200 \mathrm{mg}$ risankizumab arm and placebo was $9.0 \%(95 \% \mathrm{Cl}-8.3$ to $26 \cdot 2, p=0.31$; table 2) and between the $600 \mathrm{mg}$ risankizumab arm and placebo was $20.9 \%(2 \cdot 6$ to $39 \cdot 2, p=0.0252$; table 2). The difference in clinical remission between risankizumab and placebo at week 8 was $14.5 \%$ (2.0 to $27.0 ; \rho=0.0228)$ in the $200 \mathrm{mg}$ risankizumab arm and $21.7 \%$ ( 7.7 to 35.7 ; $\mathrm{p}=0.0023$ ) in the $600 \mathrm{mg}$ risankizumab arm (figure 2, table 2).

The proportion of patients with clinical response, endoscopic response, or deep remission at week 12 did not differ between the $200 \mathrm{mg}$ risankizumab group and placebo but an increased proportion of patients in the $600 \mathrm{mg}$ risankizumab group had these outcomes (figure 2, table 2). An increased proportion of patients had clinical response at week 8 with both risankizumab doses. More patients had endoscopic remission at week 12 in the $200 \mathrm{mg}$ and $600 \mathrm{mg}$ risankizumab dose groups compared 
with placebo (table 2). The proportion of patients with mucosal healing did not differ between risankizumab treatment and placebo (table 2).

The IBDQ assessment indicated a reduced $\mathrm{HRQ}$ oL of the randomised study population at baseline. Treatment with risankizumab resulted in a dose-dependent increase from baseline to week 12 by 7.3 points for placebo, 21.7 points for $200 \mathrm{mg}$ risankizumab, and 34.7 points for $600 \mathrm{mg}$ risankizumab (difference for $600 \mathrm{mg}$ risankizumab vs placebo $27 \cdot 3,95 \% \mathrm{Cl} 11 \cdot 7$ to $43 \cdot 0, \mathrm{p}=0 \cdot 0009$; appendix, $\mathrm{p} 8$ ).

Median CRP concentrations were reduced in both risankizumab arms compared with placebo at week $12(-6.2 \mathrm{mg} / \mathrm{L}$ [IQR -17.0 to 0.2$]$ for $200 \mathrm{mg}$ risankizumab, $-2.8 \mathrm{mg} / \mathrm{L}$ [-22.2 to -0.1$]$ for $600 \mathrm{mg}$ risankizumab, vs $2.7 \mathrm{mg} / \mathrm{L} \mathrm{[-1.2}$ to $10 \cdot 1]$ or placebo; $\rho<0.0001$ for each arm vs placebo; figure 3 ). In the post-hoc analysis, normalisation of CRP to less than the upper limit of normal $(2.87 \mathrm{mg} / \mathrm{L})$ at week 12 in patients with elevated CRP at baseline was observed in eight (24\%) of 33 patients who received $200 \mathrm{mg}$ risankizumab, eight (29\%) of 28 patients in the $600 \mathrm{mg}$ risankizumab arm, and two (7\%) of 28 patients in the placebo arm. Treatment with $600 \mathrm{mg}$ risankizumab decreased median FCP levels compared with placebo (median \% change from baseline to week $12-74.4 \%$ [IQR -91.7 to -1.0$]$ vs $2.5 \%$ [-55.5 to $107 \cdot 1]$, $p=0.0003$; figure 3 ). In the post-hoc analysis, normalisation of FCP to less than the upper limit of normal $(50 \mu \mathrm{g} / \mathrm{g})$ at week 12 in patients with elevated FCP at baseline was observed in one (3\%) of 29 patients in the $200 \mathrm{mg}$ risankizumab arm, five (16\%) of 31 patients in the $600 \mathrm{mg}$ risankizumab arm, and two (7\%) of 30 patients in the placebo arm. Additionally, plasma interleukin-22 concentration was lower with $600 \mathrm{mg}$ risankizumab treatment than with placebo (median \% change from baseline to week $12-44 \cdot 2$ [IQR-58.8 to-14.3] vs-16.7 [IQR-39.0 to 36.8]; $p=0 \cdot 0180$; figure 3).

Colon or ileum tissue was collected at baseline and at week 12 from a subset of patients (26 [63\%] for colon and 30 [73\%] for ileum in the $200 \mathrm{mg}$ risankizumab group; 27 [66\%] for colon and 26 [63\%] for ileum in the $600 \mathrm{mg}$ risankizumab group; and 26 [67\%] for colon and 22 [56\%] for ileum in the placebo group). Significant reductions in the expression of selected genes associated with interleukin-23 immune-related pathways were observed in the colon biopsies of this subset of risankizumab-treated patients compared with placebo (appendix, p 9).

Interleukin-22 gene expression was significantly reduced from baseline to week 12 in the ileum biopsies from the subset of pooled risankizumab-treated patients ( $\log 2$ fold change $-1.94 ; p=0 \cdot 003$; appendix $\mathrm{p}$ 9).

No dose-related increases for any adverse events were associated with risankizumab treatment (table 3). The most frequent adverse events were associated with the gastrointestinal tract. The most common serious adverse event was worsening of underlying Crohn's disease (appendix p 15). No deaths occurred, although serious infections were reported in three patients (abdominal, anal, and rectal abscesses, and pneumonia) in the placebo arm, one patient (pneumonia) in the $200 \mathrm{mg}$ risankizumab group, and two patients (osteomyelitis and anal abscess) in the $600 \mathrm{mg}$ risankizumab group (appendix p 15). Infusion-related reactions were mild or moderate and were reported in two $(5 \%)$ patients in the placebo group and one (2\%) patient in each of the $200 \mathrm{mg}$ and $600 \mathrm{mg}$ risankizumab groups. No differences between treatment groups were observed in physical examination, vital signs, electrocardiograph monitoring, and safety laboratory analyses.

Treatment-emergent anti-drug antibodies were detected in $4 \%$ of patients receiving risankizumab (three of 76 patients). Anti-drug antibody titre values were low $(\leq 8)$ and no neutralising antibodies were detected. Preexisting anti-drug antibodies were observed in five patients in the risankizumab dose groups and three patients in the placebo group. 


\begin{tabular}{|c|c|c|c|c|}
\hline & \multirow{2}{*}{$\begin{array}{l}\text { Placebo } \\
(n=39)\end{array}$} & \multicolumn{3}{|c|}{ Risankizumab } \\
\hline & & $\begin{array}{l}200 \mathrm{mg} \\
(\mathrm{n}=41)\end{array}$ & $\begin{array}{l}600 \mathrm{mg} \\
(\mathrm{n}=41)\end{array}$ & Pooled $(n=82)$ \\
\hline Age (years) & $36(14)$ & $39(13)$ & $40(13)$ & $39(13)$ \\
\hline \multicolumn{5}{|l|}{ Sex } \\
\hline Male & $16(41 \%)$ & $15(37 \%)$ & $16(39 \%)$ & $31(38 \%)$ \\
\hline Female & $23(59 \%)$ & $26(63 \%)$ & $25(61 \%)$ & $51(62 \%)$ \\
\hline White & $32(82 \%)$ & $36(88 \%)$ & $34(83 \%)$ & $70(85 \%)$ \\
\hline Bodyweight (kg) & $68(22)$ & $66(15)$ & $67(13)$ & $67(14)$ \\
\hline Current smoker & $7(18 \%)$ & $12(29 \%)$ & $13(32 \%)$ & $25(30 \%)$ \\
\hline Duration of disease, years & $12(9)$ & $14(9)$ & $14(10)$ & $14(9)$ \\
\hline \multicolumn{5}{|l|}{ Disease site } \\
\hline Ileum only & $5(13 \%)$ & $6(15 \%)$ & $10(24 \%)$ & $16(20 \%)$ \\
\hline Ileum and colon & $16(41 \%)$ & $25(61 \%)$ & $16(39 \%)$ & $41(50 \%)$ \\
\hline Colon only & $18(46 \%)$ & $10(24 \%)$ & $14(34 \%)$ & $24(29 \%)$ \\
\hline History of fistulising disease & $9(23 \%)$ & $7(17 \%)$ & $5(12 \%)$ & $12(15 \%)$ \\
\hline Draining fistulae at baseline & 0 & $2(5 \%)$ & $2(5 \%)$ & $4(5 \%)$ \\
\hline Previous intestinal resection for Crohn's disease & $1(3 \%)$ & 0 & $1(2 \%)$ & $1(1 \%)$ \\
\hline CDAI & $295(237-386)$ & $\begin{array}{l}311(247- \\
375)\end{array}$ & $\begin{array}{l}298(259- \\
330)\end{array}$ & $300(247-349)$ \\
\hline CDEIS & $11(8-18)$ & $12(9-17)$ & $12(8-16)$ & $12(9-17)$ \\
\hline $\mathrm{CRP}(\mathrm{mg} / \mathrm{L})$ & $14(3-34)$ & $11(5-34)$ & $8(2-29)$ & $10(4-33)$ \\
\hline $\mathrm{FCP}(\mu \mathrm{g} / \mathrm{g})$ & $\begin{array}{l}1747(672- \\
2792)\end{array}$ & $\begin{array}{l}1364 \text { (527- } \\
2319)\end{array}$ & $\begin{array}{l}1101 \text { (434- } \\
3539)\end{array}$ & $\begin{array}{l}1243(509- \\
2487)\end{array}$ \\
\hline Haemoglobin $(\mathrm{g} / \mathrm{L})$ & $125(17)$ & $126(15)$ & $127(15)$ & $126(14)$ \\
\hline \multicolumn{5}{|l|}{ Corticosteroids or IM, or both } \\
\hline Corticosteroids only & $6(15 \%)$ & $7(17 \%)$ & $9(22 \%)$ & $16(20 \%)$ \\
\hline Corticosteroids and IM & $5(13 \%)$ & $3(7 \%)$ & $3(7 \%)$ & $6(7 \%)$ \\
\hline IM only & $8(21 \%)$ & $7(17 \%)$ & $5(12 \%)$ & $12(15 \%)$ \\
\hline \multicolumn{5}{|l|}{ Previous TNF antagonist use } \\
\hline 1 & $12(31 \%)$ & $9(22 \%)$ & $9(22 \%)$ & $18(22 \%)$ \\
\hline 2 & $20(51 \%)$ & $23(56 \%)$ & $24(59 \%)$ & $47(57 \%)$ \\
\hline$\geq 3$ & $5(13 \%)$ & $7(17 \%)$ & $4(10 \%)$ & $11(13 \%)$ \\
\hline Missing & $2(5 \%)$ & $2(5 \%)$ & $4(10 \%)$ & $6(7 \%)$ \\
\hline \multicolumn{5}{|l|}{ Worst outcome of $\geq 1$ previous TNF antagonists } \\
\hline Inadequate response & $10(26 \%)$ & $16(39 \%)$ & $11(27 \%)$ & $27(33 \%)$ \\
\hline Loss of response & $21(54 \%)$ & $13(32 \%)$ & $17(41 \%)$ & $30(37 \%)$ \\
\hline Unacceptable adverse events & $1(3 \%)$ & $2(5 \%)$ & $5(12 \%)$ & $7(9 \%)$ \\
\hline Other & $2(5 \%)$ & $3(7 \%)$ & $1(2 \%)$ & $4(5 \%)$ \\
\hline Unknown & $1(3 \%)$ & $3(7 \%)$ & $2(5 \%)$ & $5(6 \%)$ \\
\hline
\end{tabular}

Data are mean (SD), $\mathrm{n}(\%)$, or median (IQR). CDAl=Crohn's Disease Activity Index. CDEIS=Crohn's Disease Endoscopic Index of Severity. $\mathrm{CRP}=\mathrm{C}$-reactive protein. $\mathrm{FCP}=$ faecal calprotectin. IM=immunomodulators. TNF=tumour necrosis factor. 
Table2: Efficacy endpoints at week 12

\begin{tabular}{|c|c|c|c|c|}
\hline & \multirow{2}{*}{$\begin{array}{l}\text { Placebo } \\
(n=39)\end{array}$} & \multicolumn{3}{|l|}{ Risankizumab } \\
\hline & & $200 \mathrm{mg}(\mathrm{n}=41)$ & $600 \mathrm{mg}(\mathrm{n}=41)$ & Pooled $(n=82)$ \\
\hline \multicolumn{5}{|c|}{ Clinical remission (primary endpoint) } \\
\hline$\eta(\%)$ & $6(15 \%)$ & $10(24 \%)$ & $15(37 \%)$ & $25(31 \%)$ \\
\hline $\begin{array}{l}\text { Difference vs placebo } \\
(95 \% \mathrm{Cl}, \mathrm{p} \text { value })\end{array}$ & & $\begin{array}{l}9 \cdot 0 \%(-8 \cdot 3 \text { to } 26 \cdot 2, \\
p=0.31)\end{array}$ & $\begin{array}{l}20 \cdot 9 \%(2.6 \text { to } 39 \cdot 2 \\
p=0.0252)\end{array}$ & $\begin{array}{l}15 \cdot 1 \%(0 \cdot 1 \text { to } 30 \cdot 1, \\
p=0 \cdot 0489)\end{array}$ \\
\hline \multicolumn{5}{|c|}{ Clinical response (secondary endpoint) } \\
\hline$\eta(\%)$ & $8(21 \%)$ & $15(37 \%)$ & $17(42 \%)$ & $32(39 \%)$ \\
\hline $\begin{array}{l}\text { Difference vs placebo } \\
(95 \% \mathrm{Cl}, \mathrm{p} \text { value })\end{array}$ & & $\begin{array}{l}16 \cdot 0 \%(-3 \cdot 2 \text { to } 35 \cdot 2, \\
\rho=0 \cdot 10)\end{array}$ & $\begin{array}{l}20 \cdot 3 \%(1 \cdot 3 \text { to } 39 \cdot 4, \\
p=0 \cdot 0366)\end{array}$ & $\begin{array}{l}18 \cdot 4 \%(2 \cdot 1 \text { to } 34 \cdot 8, \\
p=0.0273)\end{array}$ \\
\hline \multicolumn{5}{|c|}{ Endoscopic remission (secondary endpoint) } \\
\hline$\eta(\%)$ & $1(3 \%)$ & $6(15 \%)$ & $8(20 \%)$ & $14(17 \%)$ \\
\hline $\begin{array}{l}\text { Difference vs placebo } \\
(95 \% \mathrm{Cl}, \mathrm{p} \text { value })\end{array}$ & & $\begin{array}{l}12 \cdot 1 \%(0.8 \text { to } 23 \cdot 4, \\
p=0.0357)\end{array}$ & $\begin{array}{l}16 \cdot 8 \%(3.9 \text { to } 29 \cdot 7 \\
p=0.0107)\end{array}$ & $\begin{array}{l}14 \cdot 5 \%(5 \cdot 5 \text { to } \\
23 \cdot 5, p=0 \cdot 0015)\end{array}$ \\
\hline \multicolumn{5}{|c|}{ Endoscopic response (secondary endpoint) } \\
\hline$\eta(\%)$ & $5(13 \%)$ & $11(27 \%)$ & $15(37 \%)$ & $26(32 \%)$ \\
\hline $\begin{array}{l}\text { Difference vs placebo } \\
(95 \% \mathrm{Cl}, \mathrm{p} \text { value })\end{array}$ & & $\begin{array}{l}141 \%(-2 \cdot 8 \text { to } 30 \cdot 9, \\
\rho=0 \cdot 10)\end{array}$ & $\begin{array}{l}23-5 \%(5 \cdot 5 \text { to } 41 \cdot 5, \\
\rho=0 \cdot 0106)\end{array}$ & $\begin{array}{l}18 \cdot 7 \%(4 \cdot 4 \text { to } 33 \cdot 0, \\
p=0 \cdot 0104)\end{array}$ \\
\hline \multicolumn{5}{|c|}{ Mucosal healing (secondary endpoint) } \\
\hline$\eta(\%)$ & $1(3 \%)$ & $1(2 \%)$ & $3(7 \%)$ & $4(5 \%)$ \\
\hline $\begin{array}{l}\text { Difference vs placebo } \\
(95 \% \mathrm{Cl}, \mathrm{p} \text { value })\end{array}$ & & $\begin{array}{l}-0 \cdot 1 \%(-7 \cdot 0 \text { to } \\
6 \cdot 7, p=0 \cdot 97)\end{array}$ & $\begin{array}{l}4.9 \%(-4.6 \text { to } 14.3 \\
p=0.31)\end{array}$ & $24 \%(-45$ to $9 \cdot 2, p=0 \cdot 50)$ \\
\hline \multicolumn{5}{|c|}{ Deep remission (secondary endpoint) } \\
\hline$\eta(\%)$ & 0 & $1(2 \%)$ & $5(12 \%)$ & $6(7 \%)$ \\
\hline $\begin{array}{l}\text { Difference vs placebo } \\
(95 \% \mathrm{Cl}, \mathrm{p} \text { value })\end{array}$ & & $\begin{array}{l}2 \cdot 4 \%(-2 \cdot 3 \text { to } \\
7 \cdot 1, p=0 \cdot 31)\end{array}$ & $\begin{array}{l}124 \%(2 \cdot 3 \text { to } 22 \cdot 5 \\
p=0 \cdot 164)\end{array}$ & $\begin{array}{l}7 \cdot 4 \%(1 \cdot 7 \text { to } 13 \cdot 0 \\
p=0 \cdot 0107)\end{array}$ \\
\hline
\end{tabular}

Clinical remission is defined as a CDAl score $<150$. Clinical response is either a CDAl score $<150$ or a CDAl reduction of $\geq 100$ from baseline. Endoscopic remission is a CDEIS score of $\leq 4$ at week 12 ( $\leq 2$ for patients with initial isolated ileitis). Endoscopic response is a $>50 \%$ reduction in CDEIS score from baseline to week 12 . Mucosal healing is defined as the absence of mucosal ulceration. Deep remission is clinical remission and endoscopic remission. Full analysis set was used for this analysis, using non-response imputation for missing values and stratified Cochran-Mantel-Haenszel tests. CDAl=Crohn's Disease Activity Index. CDEIS=Crohn's Disease Endoscopic Index of Severity. 


\section{Figure 2: Clinical response and remission over 12 weeks}

Proportion of patients with clinical remission (A) or clinical response (B). Clinical remission is defined as a CDAI score $<150$. Clinical response is either a CDAl score $<150$ or a CDAl reduction of $\geq 100$ from baseline. Patients in whom prohibited concomitant medication to treat Crohn's disease was used before week 12 were considered as treatment failures. Intention-to-treat group was used for this analysis, using non-response imputation for missing values. $\mathrm{CDAl}=$ Crohn's Disease Activity Index.
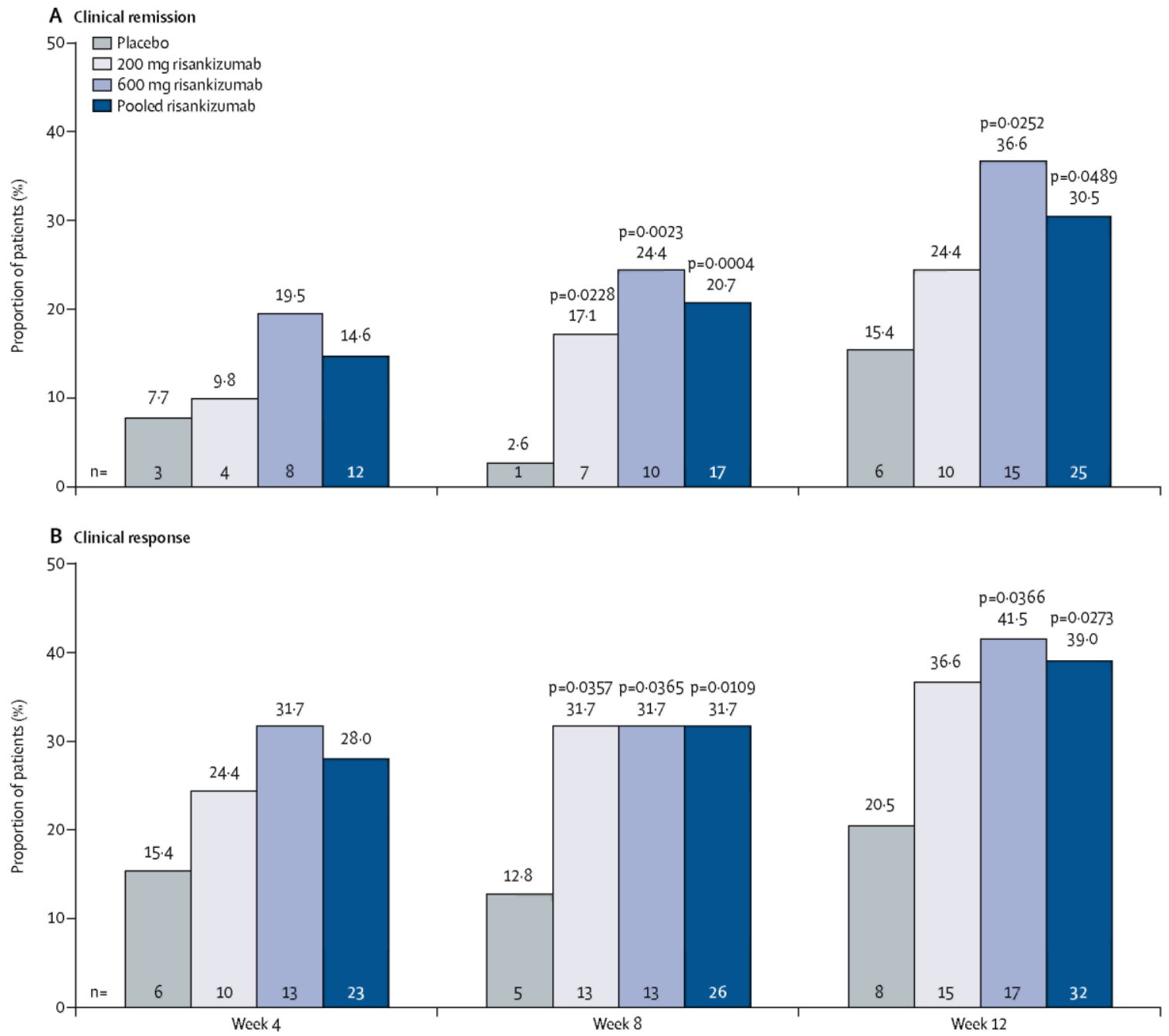
Table 3: Adverse events (on treatment at week 12)

\begin{tabular}{llll}
\hline & Placebo (n=39) & Risankizumab & \\
\cline { 2 - 3 } & & $200 \mathrm{mg}(\mathrm{n}=41)$ & $600 \mathrm{mg}(\mathrm{n}=41)$ \\
\hline Any adverse event & $32(82 \%)$ & $32(78 \%)$ & $31(76 \%)$ \\
Severe & $9(23 \%)$ & $6(15 \%)$ & $3(7 \%)$ \\
Drug related & $8(21 \%)$ & $10(24 \%)$ & $5(12 \%)$ \\
Leading to discontinuation & $6(15 \%)$ & $5(12 \%)$ & $1(2 \%)$ \\
Serious adverse events* & $12(31 \%)$ & $9(22 \%)$ & $3(7 \%)$ \\
$\quad$ Persistent or significant disability or & 0 & $1(2 \%)$ & 0 \\
incapacity & & & \\
Requiring or prolonging hospitalisation & $10(26 \%)$ & $8(20 \%)$ & $2(5 \%)$ \\
Other medically important serious & $4(10 \%)$ & $1(2 \%)$ & $1(2 \%)$ \\
event & & & \\
& & & \\
Common adverse events ${ }^{\dagger}$ & & & $3(7 \%)$ \\
Nausea & $4(10 \%)$ & $8(20 \%)$ & 0 \\
Worsening of Crohn's disease & $6(15 \%)$ & $2(5 \%)$ & $3(7 \%)$ \\
Abdominal pain & $4(10 \%)$ & $6(15 \%)$ & $6(15 \%)$ \\
Arthralgia & $3(8 \%)$ & $6(15 \%)$ & $2(5 \%)$ \\
Anaemia & $4(10 \%)$ & 0 & $4(10 \%)$ \\
Headache & $4(10 \%)$ & $6(15 \%)$ & $2(5 \%)$ \\
Vomiting & $4(10 \%)$ & $3(7 \%)$ & \\
\hline
\end{tabular}

Data are $n(\%) .{ }^{*} A$ serious adverse event was defined as any that results in death, is immediately life-threatening, results in persistent or significant disability or incapacity, requires or prolongs patient hospital stay, is a congenital anomaly or birth defect, or is an important medical event, based upon appropriate medical judgment that might jeopardise the patient and might require medical or surgical intervention. †Common adverse events were those reported in at least $10 \%$ of patients in any study arm. 
Figure 3: Change from baseline in CDAl and selected biomarkers Median CDAI (A), median CRP (B), median percentage change from baseline in FCP (C), and median percentage change from baseline in serum interleukin 22 (D). Bars are IQR. BL=baseline. CDAI=Crohn's Disease Activity Index. $C R P=C$-reactive protein. $F C P=$ faecal calprotectin. ${ }^{*} \rho<0 \cdot 0001$ for change from baseline in CRP for versus placebo. $t p=0.0003$ for median percentage change from baseline in FCP versus placebo. $\ddagger \rho=0.0160$ for median percentage change from baseline in serum interleukin 22 versus placebo
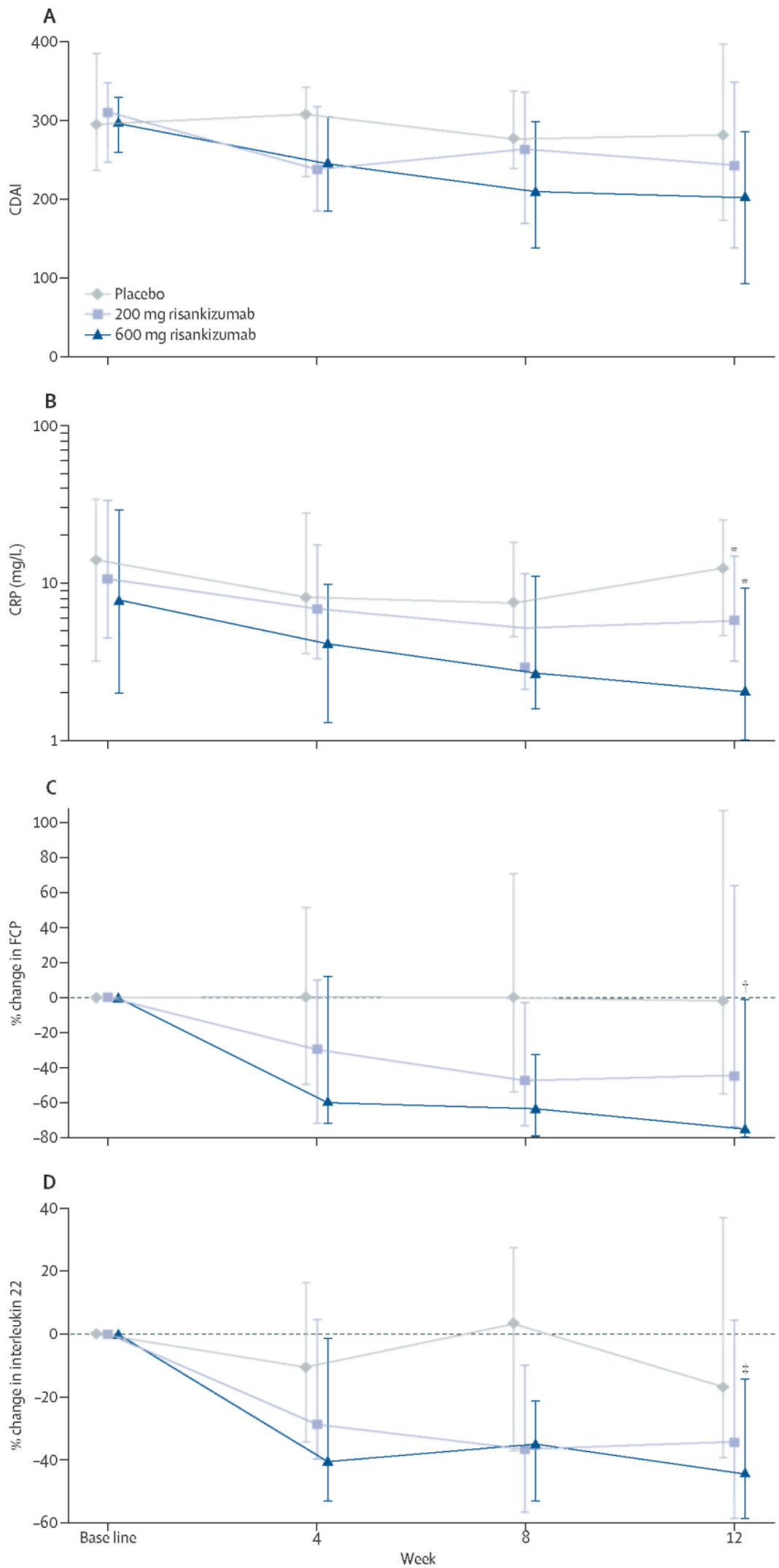


\section{Discussion}

Despite the introduction of biological therapies, an unmet need exists for patients with moderate-tosevere Crohn's disease because of high rates of treatment failure with conventional and biological therapies. ${ }^{21,22}$ About a third of patients treated with a TNF antagonist have a primary non-response, and another third develop secondary failure or intolerance to treatment. ${ }^{4}$ Patients who have had a primary non-response or secondary failure to a TNF antagonist have a lower chance of responding to subsequent treatment with different TNF antagonists ${ }^{23}$ or the integrin antagonist vedolizumab. ${ }^{24}$ Those patients who do not respond to the second-line biological therapy are at higher risk for poor outcomes. In this phase 2 trial, selective inhibition of interleukin-23 with risankizumab was superior to placebo in achieving clinical remission and response at week 12 in patients with moderate-to-severe treatmentrefractory Crohn's disease.

The differences observed for clinical response and remission between the pooled risankizumab groups and placebo were statistically significant but were also clinically meaningful in this treatmentrefractory population, in which $83(69 \%)$ of 121 patients had previously been exposed to at least two TNF antagonists and $96(79 \%)$ of 121 patients had failed at least one such treatment (because of inadequate response, loss of response, or intolerance). The difference for the $600 \mathrm{mg}$ dose achieving clinical remission compared with placebo was $20.9 \%(p=0.025)$, which represents a benefit similar to those reported for induction with infliximab or adalimumab in TNF antagonist-naive patients. ${ }^{25,26}$

Although the near resolution of symptoms associated with Crohn's disease assessed as clinical remission represents one important treatment target, clinical activity in Crohn's disease correlates poorly with objective signs of gut inflammation. ${ }^{27}$ Because chronic inflammation can lead to long-term complications such as strictures, fistulae, and dysplasia, we included endoscopic assessments in this trial to assess objectively the effects of treatment on the inflammatory process. In accordance with the observed clinical endpoints, the observed rates of endoscopic remission and deep remission, which are challenging endpoints to meet in a short-term induction study, ${ }^{28}$ also indicate the superiority of the high-dose regimen versus the lower-dose regimen and placebo.

We also found clinically meaningful increases in IBDQ for risankizumab compared with placebo. A mean change of 16 points is considered clinically meaningful for the IBDQ score ${ }^{20}$ and both the 200 $\mathrm{mg}$ and $600 \mathrm{mg}$ risankizumab groups exceeded this threshold, with $600 \mathrm{mg}$ risankizumab statistically significant versus placebo.

Both dose levels that we tested for induction in Crohn's disease were several times higher than those tested in plaque psoriasis, for which risankizumab regimens of $90 \mathrm{mg}$ and $180 \mathrm{mg}$ given subcutaneously at weeks 0,4 , and 12 showed superior efficacy versus ustekinumab at 12 weeks in a phase 2 study. ${ }^{29}$ Our dose selection was based on observations with TNF antagonists that indicated the need for higher induction doses in Crohn's disease compared with other indications, which might result from lower drug exposure because of intestinal protein loss or a larger burden of target molecules in the inflamed gut in inflammatory bowel diseases, or both. ${ }^{30,31}$ In keeping with this hypothesis, all efficacy outcomes favoured the $600 \mathrm{mg}$ dose. The observed associations between risankizumab exposure and CDAI response and remission as well as endoscopic activity (CDEIS response) should be evaluated in future studies.

Reductions in expression of biomarkers in blood and tissue were consistent with blockade of interleukin-23-mediated gut inflammation. ${ }^{7}$ Larger decreases in serum CRP and FCP concentrations were observed at 12 weeks in the risankizumab groups in comparison with the placebo group. Changes in gene expression observed in colon tissue indicated that multiple pathways associated with the interleukin-23 axis weredownregulatedbyl2weeks in patients treated with risankizumab. Activated Thl7 and ILC3 cells from patients with inflammatory bowel disease characteristically produce interleukin-22, ${ }^{932}$ and treatment with risankizumab decreased interleukin-22 expression in ileum biopsies and in circulation, consistent with the expected effects of blockade of the interleukin-23 axis. Collectively, these data suggest that selective inhibition of interleukin-23 through targeting of the 
interleukin-23 pl9 subunit might be an effective induction therapy for moderate-to-severe Crohn's disease.

In this short-term trial, risankizumab showed a favourable safety profile. We observed no association between drug dose and the incidence of adverse events, and we detected no dose-dependent safety signal. The most common serious adverse event was worsening of underlying Crohn's disease. However, the limited duration of the trial and the small number of patients evaluated did not allow an exhaustive assessment of the safety and tolerability of the drug. Treatment-emergent anti-drug antibodies were detected in $4 \%$ of patients but were of low titres and were not neutralising. The observation of low titre pre-existing anti-drug antibodies in eight patients is not unusual using highly sensitive assays and such antibodies are not usually clinically relevant. ${ }^{33}$

A key strength of this study was its design. To be enrolled, patients needed to have baseline clinical and endoscopic activity, which was scored using central reading by a masked reviewer. Endoscopic outcome was also assessed in all patients as a secondary endpoint.

The major limitations of our study were the low number of patients evaluated, resulting in relatively imprecise estimates of treatment effects, and the short study duration. Although the small number of TNF antagonist-naive patients randomised in this trial precludes the extrapolation of the observed effects beyond the study population, past trials ${ }^{12,23}$ in TNF antagonist-experienced patients with different biological treatments have generally shown a lower treatment effect in TNF antagonist-naive patients. Another methodological limitation inherent to all clinical trials in patients with Crohn's disease is the lack of clinical validation of endoscopic endpoints. However, the operating properties of the CDEIS used in this study are well characterised and have been successfully used in previous clinical trials. $^{34}$ Furthermore the definition of endoscopic remission is consistent with expert panel recommendations. ${ }^{35}$

In this short-term proof-of-concept trial in patients with moderate-to-severe Crohn's disease, in most of whom treatment with a TNF antagonist had previously failed, treatment with risankizumab achieved higher clinical and endoscopic remission rates than placebo at week 12 . These results suggest that specific blockade of interleukin-23 via inhibition of pl9 might be a viable therapeutic approach in Crohn's disease and warrants further investigation in larger studies with longer duration.

\section{Contributors}

BGF wrote the initial draft. All authors approved the manuscript for submission and vouch for the veracity and completeness of the data and the fidelity of the study to the protocol. The study site and investigator details are in the appendix ( $p$ 2). BGF, WJS, GD'H, JP, AK, SS, PS, SV, SJP, DBH, and WOB contributed to study design. BGF, WJS, GD'H, JP, AK, MF, EL, DF, OD, US, K-JK, MFN, and SS contributed to data collection. All listed authors contributed to data analysis, data interpretation, and writing and review of the manuscript.

\section{Declaration of interests}

BGF reports personal fees from Receptos, during the conduct of the study; grants from Sanofi; grants and personal fees from AbbVie, Amgen, AstraZeneca, Bristol-Myers Squibb, Janssen Biotech/Centocor, Johnson \& Johnson/Janssen, Pfizer, Receptos, and Takeda; personal fees from Actogenix, Akros, Albireo Pharma, Allergan, Avaxia Biologies Inc, Avir Pharma, Axcan, Baxter Healthcare Corporation, Biogen Idee, Boehringer Ingelheim, Calypso Biotech, Celgene, Elan/Biogen, enGene, Ferring, Genentech/Roche, GiCare Pharma, Gilead, Given Imaging, GlaxoSmithKline, Ironwood, Kyowa Hakko Kirin Co, Ltd, Lilly, Lycera Biotech, Merck, Mesoblast Pharma, Millennium, Nestlé, Novo Nordisk, Novartis, Prometheus Therapeutics and Diagnostics, Protagonist, Salix, Shire, Sigmoid Pharma, Synergy Pharma, Teva Pharma, TiGenix, Tillotts, UCB, Vertex, VHsquared, Wyeth, Zealand, and Zyngenia, outside the submitted work. BGF is CEO and Senior Scientific Director of 
Robarts Clinical Trials (Western University, London, ON, Canada). WJS reports grants, personal fees, and non-financial support from Boehringer Ingelheim during the conduct of the study; grants from Exact Sciences, the American College of Gastroenterology, and the Broad Foundation; grants and personal fees from Prometheus Laboratories, AbbVie, Amgen, Boehringer Ingelheim, Takeda, Atlantic Pharmaceuticals, Janssen, Bristol-Myers Squibb, Gilead Sciences, GlaxoSmithKline, Genentech, Pfizer, Nutrition Science Partners, and Receptos; personal fees from Kyowa Hakko Kirin, Millennium Pharmaceuticals, Celgene Cellular Therapeutics, Santarus, Salix Pharmaceuticals, Catabasis Pharmaceuticals, Vertex Pharmaceuticals, Warner Chilcott, Cosmo Pharmaceuticals, Ferring Pharmaceuticals, Sigmoid Biotechnologies, Tillotts Pharma, Am Pharma BV, Dr August Wolff GmbH \& Co KG, Avaxia Biologies, Zyngenia, Ironwood Pharmaceuticals, Index Pharmaceuticals, Nestle, Lexicon Pharmaceuticals, UCB Pharma, Orexigen, Luitpold Pharmaceuticals, Baxter Healthcare, Ferring Research Institute, Novo Nordisk, Mesoblast, Shire, Ardelyx, Actavis, Seattle Genetics, Medlmmune (AstraZeneca), ActoGeniX NV, Lipid Therapeutics Gmbh, Eisai, Qu Biologies, Toray Industries, Teva Pharmaceuticals, Eli Lilly, Chiasma, TiGenix, Adheron Therapeutics, Immune Pharmaceuticals, Celgene, Arena Pharmaceuticals, Ambrx, Akros Pharma, Vascular Biogenics, Theradiag, Forward Pharma, Regeneron, Galapagos, Seres Health, Ritter Pharmaceuticals, Theravance Biopharma, Palatin, Biogen, and the University of Western Ontario (owner of Robarts Clinical Trials), outside the submitted work. WJS reports patents related to the use of topical azathioprine to treat inflammatory bowel disorders (US 5691 343), topical formulations of azathioprine to treat inflammatory bowel disorders (US 5,905,081), colonic delivery of nicotine to treat inflammatory bowel disease (South African patent 97/1020; US 5,846,983, 5,889,028, and 6,166,044; Mexico patent 209636; Europe patents 0954337 and 893998; Hong Kong patent HK1019043; China patent ZL97192177; Czech patent 293616; Canada patent 2,246,235), the use of azathioprine to treat CD (US 5,733,915), azathioprine compositions for colonic administration (New Zealand patent 306062; Singapore patent 45647; Australia patent 707168; Czech patent 290428), intestinal absorption of nicotine to treat nicotine responsive conditions (Australia patent 718052; US 6,238,689), the use of topical azathioprine and thioguanine to treat colorectal adenomas (US 6,166,024), enema and entericcoated oral dosage forms of azathioprine (US 6,432,967), a pharmaceutical composition for the treatment of inflammatory bowel disease (US 7341741), intestinal absorption of nicotine to treat nicotine responsive conditions (Canada patent 2,260,909), and obesity treatment and device (US 7,803,195 B2). GD'H reports personal fees from Boehringer Ingelheim, during the conduct of the study; personal fees from AbbVie, Ablynx, Amakem, AM Pharma, Avaxia, Biogen, Bristol-Myers Squibb, Celgene, Celltrion, Cosmo, Covidien, Engene, Ferring, Galapagos, GlaxoSmithKline, Hospira, Johnson and Johnson, Medimetrics, Millennium/Takeda, Mitsubishi Pharma, Merck Sharp Dome, Mundipharma, Novo Nordisk, Pfizer, Prometheus Laboratories/Nestlé, Receptos, Robarts Clinical Trials, Salix, Sandoz, Setpoint, Shire, Teva, Tillotts, TopiVert, Versant, and Vifor, outside the submitted work. JP reports personal fees from Boehringer Ingelheim, during the conduct of the study; personal fees from AbbVie, Galapagos, Genentech Roche, Pfizer, Takeda, TiGenix, and TopiVert, outside the submitted work. AK reports grants, and non-financial support from Boehringer Ingelheim, during the conduct of the study; personal fees from Boehringer Ingelheim, Ferring, Genentech, GlaxoSmithKline, Hospira, Janssen, Kymab, Second Genome, and VHsquared, outside the submitted work. MF reports personal fees and non-financial support from Boehringer Ingelheim, during the conduct of the study; grants, personal fees, and non-financial support from Takeda, personal fees and non-financial support from AbbVie, Falk, Ferring, Janssen, MSD, and Tillotts; personal fees from Chiesi, Mitsubishi Tanabe, and Zeria Pharmaceutical Co., outside the submitted work. EL reports grants, personal fees, and non-financial support from AbbVie and MSD; personal fees from Ferring, Takeda, Celltrion, Mundipharma, Hospira, and Janssen, outside the submitted work. DF reports educational grants, personal fees and non-financial support from AbbVie and MSD; personal fees from Amgen, Ferring, Takeda, Mundipharma, Hospira, and Pfizer, outside the submitted work. US reports grants from Boehringer Ingelheim, during the conduct of the study; grants from Pfizer, Janssen, Roche, Gilead, Salix, and Mitsubishi; personal fees from MSD; non-financial support from Takeda, outside the submitted work. MFN reports personal fees from MSD Sharp \& Dohme GmbH, PPM Services SA, Index Pharmaceuticals $A B$, Shire $\mathrm{GmbH}$, Boehringer Ingelheim $\mathrm{GmbH} \& \mathrm{Co}$. KG, 
Janssen-Cilag GmbH, Pentax Europe GmbH, Tillotts Pharma AG, e.Bavarian Health GmbH, and Takeda Pharma GmbH \& Co. KG; grants from German Research Council and German Cancer Aid, outside the submitted work. In addition, MFN has a patent anti-interleukin-12 therapy in Crohn's disease issued. S S reports personal fees from Boehringer Ingelheim, during the conduct of the study; personal fees from Boehringer Ingelheim, Medlmmune, and Janssen, outside the submitted work. OD and K-JK report no competing interests. PS, CP, BL, SV, SJP, IH, AS, DBH, and WOB are employed by Boehringer Ingelheim. PS, SV, SJP, and WOB report a patent BI case 09-0645-US-4pending.

\section{Acknowledgments}

Editorial assistance in the development of this manuscript was provided by Esther Race and Leigh Church of Succint Choice (London, UK) and funded by Boehringer Ingelheim (Ingelheim, Germany). We thank Patrick Baum (Boehringer Ingelheim, Ingelheim, Germany) for technical expertise in RNA sequencing, Oliver Kleiner (Boehringer Ingelheim, Ingelheim, Germany) for plasma biomarker expertise, Richard Vinisko (Boehringer Ingelheim, Ridgefield, CT, USA) for biomarker statistical analysis, and Kelly Coble and Steve Norris (Boehringer Ingelheim, Ridgefield, CT, USA) for their technical expertise with bioanalytical assays for risankizumab and anti-drug antibody.

\section{References}

1 Baumgart DC, Sandborn WJ. Crohn's disease. Lancet 2012; 380:1590-605.

2 Sandborn WJ, Feagan BG, Stoinov S, et al. Certolizumab pegol for the treatment of Crohn's disease. N Engl J Med 2007; 357: 228-38.

3 Targan SR, Feagan BG, Fedorak RN, et al. Natalizumab for the treatment of active Crohn's disease: results of the ENCORE Trial. Gastroenterology 2007; 132:1672-83.

4 Peyrin-Biroulet L, Deltenre P, de Suray N, Branche J, Sandborn WJ, Colombel JF. Efficacy and safety of tumor necrosis factor antagonists in Crohn's disease: meta-analysis of placebo-controlled trials. Clin Castro Hepatol 2008; 6: 644-53.

5 Gordon JP, McEwan PC, Maguire A, Sugrue DM, Puelles J. Characterizing unmet medical need and the potential role of new biologic treatment options in patients with ulcerative colitis and Crohn's disease: a systematic review and clinician surveys. Eur J Gastroenterol Hepatol 2015; 27: 804-12.

6 Lichtenstein GR, Sbreu MT, Cohen R, Tremaine W American Gastroenterological Association Institute technical review on corticosteroids, immunomodulators, and infliximab in inflammatory bowel disease. Rev Gastroenterol Mex 2006; 71: 351-401.

7 Neurath MF. IL-23: a master regulator in Crohn disease. Nat Med 2007; 13: $26-8$.

8 Duerr RH, Taylor KD, Brant SR, et al. A genome-wide association study identifies IL23R as an inflammatory bowel disease gene. Science 2006; 314:1461-63.

9 Geremia A, Arancibia-Carcamo CV, Fleming MP, et al. IL-23-responsive innate lymphoid cells are increased in inflammatory bowel disease. J Exp Med 2011; 208:1127-33.

10 Campa M, Mansouri B, Warren R, Menter A. A review of biologic therapies targeting IL-23 and IL17 for use in mo derate-to-severe plaque psoriasis. Dermatol Ther 2016; 6:1-12.

11 Sandborn WJ, Gasink C, Gao LL, et al. Ustekinumab induction and maintenance therapy in refractory Crohn's disease. N Engl J Med 2012; 367:1519-28.

12 Feagan BG, Sandborn WJ, Gasink C, et al. Ustekinumab as induction and maintenance therapy for Crohn's disease. N Engl J Med 2016; 375:1946-60. 
13 Hueber W, Sands BE, Lewitzky S, et al. Secikunmab, a human anti-IL-17a monoclonal antibody, for moderate to severe Crohn's disease: unpected results of a randomised, double-blind placebocontrolled trial. Gut 2012; 61:1693-700.

14 Targan SR, Feagan B, Vermeire S, et al. A randomised, double-blind, placebo-controlled phase 2 study of brodalumab in patients with moderate-to-severe Crohn's disease. Am J Gastroenterol 2016; 111: $1599-607$

15 Singh S, Kroe-Barrett RR, Canada KA, et al. Selective targeting of the IL23 pathway: generation and characterization of a novel high-affinity humanized anti-IL23A antibody. mAbs 2015; 7: 778-91.

16 Brunda MJ, Luistro L, Warrier RR, et al. Antitumor and antimetastatic activity of interleukin 12 against murine tumors. J Exp Med 1993; 178:1223-30.

17 Stobie L, Gurunathan S, Prussin C, et al. The role of antigen and IL-12 in sustaining Thl memory cells in vivo: IL-12 is required to maintain memory/effector Thl cells sufficient to mediate protection to an infectious parasite challenge. Proc Natl Acad Sci USA 2000; 97: 8427-32.

18 Krueger JG, Ferris LK, Menter A, et al. Anti-IL-23A mAb BI 655066 for treatment of mo de rateto-severe psoriasis: safety, efficacy, pharmacokinetics, and biomarker results of a single-rising-dose, randomized, double-blind, placebo-controlled trial. J Allergy Clin Immunol 2015; 136:116-24.

19 Levesque BG, Sandborn WJ, Ruel J, et al. Converging goals of treatment of inflammatory bowel disease from clinical trials and practice. Gastroenterology 2015; 148: 37-51.

20 Irvine EJ, Feagan B, Rochon J, et al. Quality of life: a valid and reliable measure of therapeutic efficacy in the treatment of inflammatory bowel disease. Canadian Crohn's Relapse Prevention Trial Study Group. Gastroenterology 1994; 106: 287-96.

21 Matsuoka K, Kanai T. Mechanism and therapeutic strategy of secondary failure to anti-tumor necrosis factor-alpha monoclonal antibody treatment for Crohn's disease. Digestion 2013; 88:17-19.

22 Terdiman JP, Gruss CB, Heidelbaugh JJ, et al. American Gastroenterological Association Institute guideline on the use of thiopurines, methotrexate, and anti-TNF-alpha biologic drugs for the induction and maintenance of remission in inflammatory Crohn's disease. Gastroenterology 2013; 145:1459-63.

23 Gisbert JP, Marin AC, McNicholl AG, Chaparro M. Systematic review with meta-analysis: the efficacy of a second anti-TNF in patients with inflammatory bowel disease whose previous anti-TNF treatment has failed. Aliment Pharmacol Ther 2015;41:613-23.

24 Sandborn WJ, Feagan BG, Rutgeerts $P$, et al. Vedolizumab as induction and maintenance therapy for Crohn's disease. N Engl J Med 2013; 369: 711-21.

25 Targan SR, Hanauer SB, van Deventer SJ, et al. A short-term study of chimeric monoclonal antibody cA2 to tumor necrosis factor alpha for Crohn's disease. Crohn's Disease cA2 Study Group. $N$ Engl J Med 1997; 337:1029-35.

26 Hanauer SB, Sandborn WJ, Rutgeerts P, et al. Human anti-tumor necrosis factor monoclonal antibody (adalimumab) in Crohn's disease: the CLASSIC-I trial. Gastroenterology 2006; 130: 323-33.

27 Peyrin-Biroulet L, Reinisch W, Colombel JF, et al. Clinical disease activity, C-reactive protein normalisation and mucosal healing in Crohn's disease in the SONIC trial. Gut 2014; 63: 88-95.

28 Rutgeerts P, Van Assche G, Sandborn WJ, et al. Adalimumab induces and maintains mucosal healing in patients with Crohn's disease: data from the EXTEND trial. Gastroenterology 2012; 142:1102-11.

29 Papp K, Blauvelt A, Bukhalo M, et al. Selective blockade of IL-23pl9 with BI 655066 is associated with clinical responses superior to ustekinumab in patients with moderate-to-severe plaque psoriasis: Results from a 48-week Phase II study. J Am Acad Dermatol 2016; 74(suppl 1):AB274. 
30 Ordas I, Feagan BG, Sandborn WJ. Therapeutic drug monitoring of tumor necrosis factor antagonists in inflammatory bowel disease. Clin Gastro Hepatol 2012; 10:1079-87

31 Brandse JF, van den Brink GR, Wildenberg ME, et al. Loss of infliximab into feces is associated with lack of response to therapy in patients with severe ulcerative colitis. Gastroenterology 2015; 149: 350-55.

32 Kleinschek MA, Boniface K, Sadekova S, et al. Circulating and gut-resident human Thl7 cells express CD161 and promote intestinal inflammation. J Exp Med 2009; 206: 525-34.

33 van Schie KA, Wolbink GJ, Rispens T Cross-reactive and pre-existing antibodies to therapeutic antibodies-effects on treatment and immunogenicity. mAbs 2015; 7: 662-71.

34 Khanna R, Bouguen G, Feagan BG, et al. A systematic review of measurement of endoscopic disease activity and mucosal healing in Crohn's disease: recommendations for clinical trial design. Inflamm Bowel Dis 2014; 20:1850-61.

35 Vuitton L, Marteau P, Sandborn WJ, et al. IOIBD technical review on endoscopic indices for Crohn's disease clinical trials. Gut 2016; 20:1447-55. 